\title{
The Influence of Out-of-school High School Experiences on Engineering Iden- tities and Career Choice
}

\section{Dr. Allison Godwin, Purdue University, West Lafayette}

Allison Godwin, Ph.D. is an Assistant Professor of Engineering Education at Purdue University. Her research focuses on increasing female enrollment in engineering, how students' attitudes and beliefs affect their choices and their learning, and how to improve engineering education for all students - especially those from underrepresented groups. Dr. Godwin graduated from Clemson University with a B.S. in Chemical Engineering and Ph.D. in Engineering and Science Education. She is the recipient of a 2014 American Society for Engineering Education Educational Research and Methods Division Apprentice Faculty Grant. She also was an NSF Graduate Research Fellow for her work on female empowerment in engineering which won the National Association for Research in Science Teaching 2015 Outstanding Doctoral Research Award.

\section{Gerhard Sonnert, Science Education Department, Harvard-Smithsonian Center for Astrophysics}

Gerhard Sonnert is a Research Associate at the Harvard-Smithsonian Center for Astrophysics and an Associate of the Harvard Physics Department. He received master's and doctorate degrees in Sociology from the University of Erlangen, Germany, and a Master's in Public Administration from Harvard University. One of his major research interests has been the impact of gender on science careers. This research has resulted in two books (both authored with the assistance of Gerald Holton): Who Succeeds in Science? The Gender Dimension and Gender Differences in Science Careers: The Project Access Study.

\section{Dr. Philip Michael Sadler, Harvard Smithsonian Center for Astrophysics}

Philip Sadler holds a B.S. in Physics from MIT and an Ed.D. from Harvard. He co-authored the first integrated computer and laboratory introductory calculus course in 1975. He has taught middle school mathematics, engineering, and science and both undergraduate science and graduate teaching courses at Harvard. His research interests include assessment of students' misconceptions and how they change with instruction, K-12 curriculum development, the transition to college of students who wish to purse STEM careers, and the professional development teachers. Dr. Sadler won the Journal of Research in Science Teaching Award, the AIP's Computers in Physics Prize, the American Astronomical Society Education Prize, and the AAPT's Millikan Medal. He holds five patents. Materials and curricula developed by Dr. Sadler are used by an estimated fifteen million students every year. 


\title{
The Influence of Out-of-school High School Experiences on Engineering Identities and Career Choice
}

\begin{abstract}
Students' engineering career choices are not well understood. There are a variety of factors, including irrational ones, which affect students' ultimate career decisions. Among them, out-ofschool experiences in high school can impact their career interests and decisions. We examined differences in incoming engineering students' high school extracurricular experiences, and how those experiences influenced current and future selves, as well as career plans. The data for this work come from a national survey, distributed in Fall 2013, of 15,847 students from 27 different institutions across the U.S. Among the students, 2,007 students were interested in an engineering career.

Chi-square tests were conducted to examine differences in male and female engineering students' reported out-of-school experiences in high school. Additionally, regression analysis was used to study how students' high school experiences and interests predicted their engineering identity both now and in the future. Gender interactions were also examined to see if a particular interest was more or less important for women in forming their engineering identities. Students who were interested in tinkering, chemistry, engaging with the natural world, and participating in science competitions were more likely to have defined engineering perceptions of their selves now and in the future. Moreover, gender interactions were found for students who tinkered with mechanical and electrical devices and talked about science. Finally, students' engineering identities, both now and in the future, were used to predict engineering choice.
\end{abstract}

\section{Background}

Students' self-identification with engineering is vitally important to their recruitment and retention in engineering as calls from the U.S. President have emphasized the need for one million new STEM graduates in the next decade to maintain the country's global competitiveness $^{1}$. Others have documented a need for not just more engineers ${ }^{2,3}$, but a more diverse workforce of engineers which can lead to greater innovation ${ }^{4}$. Understanding why students choose engineering in college can help identify avenues through which more students can see themselves as engineers and choose engineering as a career. Prior work has shown that developing math and science related identities and developing grit to accomplish far off goals is important for students to choose and persist in engineering fields ${ }^{5}$. Developing interests in STEM-related activities can foster identity development in related fields and ultimately engineering choice.

Understanding how differences in students' high school experiences and interests predict differences students' identification with engineering and engineering choice in college can begin to address this need. This work examines how out-of-school experiences in high school influence students identification with engineering both now and in the future. Additionally, these identities at both time points were used to predict engineering choice over other STEM-related disciplines. 
We utilized the framework of possible selves to examine students' self-beliefs of who they are now and who they could be in the future as predicted by high school experiences. Possible selves represent individuals' ideas of "who they might become, who they would like to become, and who they wish to avoid becoming” (p. 954) ${ }^{6}$, and thus provide a conceptual link between students' current identities, motivation, and future role identities. Role identities are the role (or character) people play when holding specific social positions in groups, like being an engineer ${ }^{7}$. Students' selves are the types of people or roles that they are or may become. Students are motivated to pursue images of their future selves that they hope for and strive against possible selves they do not want to become. Additionally, thinking about the future or working to develop future possible selves has been shown to increase interest and ability to succeed in school ${ }^{8}$. Understanding the future component of student self-concept can provide insight into students' goals and engineering trajectories.

Additionally, exploring how students current identities in engineering relate to a possible self in engineering can highlight ways in which students may persist over time. Possible selves can facilitate optimism and persistence in students when they believe that their current self is mutable into their possible self over time ${ }^{9}$. In fact, this self can serve to guide student behavior by showing a path to connect the present with the future. This connection can provide ways in which engineering identity is developed and students continue in engineering studies to obtain an engineering degree. Prior research has shown that this motivation is based on the context in which a possible self is situated. The fit between current identity, context, and future self facilitates student motivation to work on specific goals and succeed on academic tasks ${ }^{10}$.

For students' transition into the workforce, previous research has shown that an important aspect of a person's work identity is situated in the future ${ }^{11,12}$. In regards the career domain, possible selves have been considered to be an important energizer of career behavior ${ }^{11}$, and career transitions and change are supposed to be fueled by modifications in the person's set of possible selves $^{13}$. The future components of possible selves are inextricably linked to currently held identities. Envisioned selves in the future are shaped and mediated by who students see themselves as now; therefore, possible selves provides a framework for understanding not only the embodiment of future goals, but also the connection between identity and motivation to achieve these goals.

The development of an engineering possible self is guided by current images of students' beliefs of who they are and past experiences ${ }^{14}$. Often, students do not feel like the kind of people that can do engineering early on in their engineering coursework ${ }^{15}$. The motivation to continue in an engineering career trajectory in spite of the difficult course work and time demands of an engineering major may be explained by students' beliefs that they can be engineers in the future 16. We focused on students' extracurricular experiences because, until college, most high school curriculum is undifferentiated for students intending on majoring in a variety of STEM fields in college $^{17}$. Understanding how these experiences outside of traditional course work may help provide opportunities for students to engage with science- and engineering-related activities to spark an interest in engineering in college and create hoped for possible selves in an engineering field. However, much of the research on possible selves has focused on the types of possible selves created rather than the content of these possible selves and the effects on outcomes like 
career choice ${ }^{9,18,19}$. This work extends our understanding of possible selves in relation to engineering for students in the transition from high school to college.

Overall, there has been little research on the self-selection effects governing participation, let alone career outcomes, of out-of school experiences ${ }^{20,21}$. The National Research Council stated that out-of-school science experiences have a positive impact on education because they promote interest in science within the real world ${ }^{22}$. Fostering interest in a science-related area has been shown to motivate STEM career choice and persistence ${ }^{21,23-25}$. Research on informal science has begun to examine how these experiences influence students' career choice. These experiences include museum visits, science groups or clubs, and science competitions, which are structured ${ }^{22}$, while other unstructured activities are less frequently studied. These activities include conversations or socializing around science, tinkering with objects, personal science hobbies, and reading non-fiction science and science fiction ${ }^{21,26,27}$. Additionally, gender differences have been shown in students' out-of-school experiences. Females more often reported biology-related experiences (i.e. observing birds or plants) while males more often reported physics-related experiences (i.e. made a bow and arrow or played with electric batteries and bulbs) ${ }^{28}$. However, no studies have examined the impact of these experiences on the choice of engineering in college for males and females.

Additionally, women continue to be underrepresented in engineering as a whole, with approximately one-fifth of bachelor's degrees awarded to women each year in the U.S. Substantial differences in female participation exist across engineering disciplines ${ }^{29}$. However, the reasons for these differences has not been fully investigated. A greater number of talented engineers is needed, and understanding how to increase diversity in engineering through out-ofschool experiences affect choices of engineering careers will contribute to improving the types and numbers of engineers entering the workforce to meet the challenges of the $21^{\text {st }}$ century.

In this paper, we used the lens of possible selves to address the following research questions: 1) How do students' out-of-school high school experiences affect students' engineering identity now and in the future?; 2) Are these experiences different by gender?; and 3) How does engineering identity now and in the future predict students' choice of engineering in college?

\section{Methods}

The data for this study come from the Outreach Programs and Science Career Intentions (OPSCI) survey given in the fall of 2013 to incoming students at U.S. institutions of higher education that participated the Science, Technology, Engineering, and Mathematics Talent Expansion Program (STEP) funded by National Science Foundation (NSF DUE 1161052). This program supports initiatives geared toward increasing the number of students receiving associate or baccalaureate degrees in the STEM fields. The survey was administered in freshman English courses, typically required as a general education credit, to gain a representative sample of both STEM and non-STEM students at each participating university.

In the typical cases, personalized recruitment emails were sent to the Chairs of the English Department, specifically mentioning the STEP researcher involved at their university. Of the 150 institutions, 104 never responded to repeated inquiries. Of the 46 that responded, 27 (59\%) 
participated with at least one professor. These responses included 23 four-year institutions and 4 two-year institutions. Of the 535 instructors who initially agreed to administer the survey, 414 instructors (77\%) followed through, returning 15,847 completed student surveys. The surveys were administered in hardcopy during class time so that student participation was close to $100 \%$. Of the total number of students who took the OPSCI survey, 2,007 students indicated an interest in an engineering career.

The questions on the OPSCI survey were to a considerable portion identical with the questions that had already been developed and successfully used in an earlier study titled "Persistence Research in Science and Engineering” (PRiSE - NSF GSE 062444). Other questions were created specifically for the OPSCI survey by the project team. The OPSCI survey was pilot tested with students at a Southern university to ensure construct validity and the time it took for survey completion. Test-retest reliability of the survey was established by administering the survey to 57 students at that same university twice in an interval of about two weeks. For continuous variables, the Pearson correlation coefficient between the test and retest answers served as a measure of reliability; for categorical variables, Cohen's kappa was used. The overall means were and 0.73 for the correlation coefficients, and 0.59 for the Cohen's kappas.

The students interested in the seven listed engineering disciplines were compared on their students' high school experiences and interests using chi-square tests. The effects of these high school experiences on their current engineering identity and possible selves were investigated using multinomial regression analysis. Differences in out-of-school experiences by gender were also examined. Finally, choice of engineering in college was predicted based on students reported engineering identities both now and in the future using multivariate logistic regression for either a choice of engineering or some other degree. Students indicated if they had these experiences (see Table 1 for a list of interests and experiences) during high school on a binary scale ( 0 = "No," and 1 = "Yes"). Additionally, students were asked to rate their identity as an engineer by asking, "I see myself as an engineer now," and "I see myself as an engineer in the future,” from 0 -“no, not at all” to 5 - "yes, very much” on an anchored scale. The engineering choice variable was created by determining if a student indicated that any of the engineering disciplines in the survey were a desired career at the beginning of college $(0=$ no disciplines selected, 1 = one or more engineering discipline selected). All analyses were conducted using the statistical program $\mathrm{R}^{30}$. The cutoff for significance was set at $\alpha<0.01$ level to reduce the risk of Type I error.

Table 1: Abbreviations for interests and experiences used in analyses.

\begin{tabular}{ll}
\hline Abbreviation & Reported Interest/Experience \\
\hline tinkm & Tinkered with mechanical devices (e.g., rifle, bow and arrow, car jack, \\
tinke & pulleys, wheelbarrow, sewing machine) \\
chem & $\begin{array}{l}\text { Tinkered with electrical devices (e.g., cars, batteries and bulbs, radio, TV) } \\
\text { Mixed chemical/materials. Engaged with chemistry sets, kitchen } \\
\text { chemistry }\end{array}$ \\
plant & Took care of or trained an animal \\
star & $\begin{array}{l}\text { Planted seeds, watched plants grow, watched animal behavior, collected } \\
\text { things in nature (e.g., butterflies, rocks) }\end{array}$ \\
& Observed or studied stars and other astronomical objects
\end{tabular}




\begin{tabular}{ll}
$\begin{array}{l}\text { group } \\
\text { comp } \\
\text { nonfic }\end{array}$ & $\begin{array}{l}\text { Participated in science groups/clubs/camps } \\
\text { Participated in science/math competition(s) } \\
\text { Read/Watched non-fiction science }\end{array}$ \\
\hline Abbreviation & Reported Interest/Experience \\
\hline scifi & Read/Watched science fiction \\
game & Played computer/video games \\
prog & Wrote computer programs or designed web pages \\
talk & Talked with friends or family about science \\
\hline \hline
\end{tabular}

\section{Results and Discussion}

Significant differences were found in male and female engineering students' indicated out-ofschool interests or experiences during grades 9-12 of high school (Table 2). More male students reported tinkering with mechanical or electrical devices, reading or watching science fiction, playing computer/video games, and writing computer programs or designing web pages. More female students reported interacting with the natural world and participating in science groups/clubs/camps. There were no significant differences by gender in engaging with chemistry, taking care of animals, participating in science/math competitions, reading or watching non-fiction science, and talking with friends or family about science. Many math and science competitions or programs involve multiple aspects of engineering and may attract a wide variety of students interested in engineering ${ }^{31-33}$.

The differences are consistent with previous work that shows that some gender stereotypes manifested themselves in students' extracurricular interests and experiences ${ }^{34,35}$. However, many of the experiences that have been shown to foster an interest in STEM areas ${ }^{26,27}$ were equally reported by male and female engineering students. Differences between engineering students and the whole population averages can be seen. All students who indicated an interest in engineering more often reported STEM-related out-of-school experiences than the average student population.

The most substantial differences were in the areas of tinkering and writing computer programs or designing web pages. These experiences are more stereotypically masculine ${ }^{35}$, and research on fostering interests in engineering, especially mechanical, electrical, and computer, has focused on these interest areas as a path into engineering ${ }^{36}$. However, the culture of engineering and emphasis on these skills and activities have created an environment and expectation of incoming students that is exclusionary. McIlwee and Robinson ${ }^{37}$ illustrate this point well:

“As long as engineering carries with it the 'tinkering' image, young women will not be drawn to it unless they see themselves and as capable of tinkering too.

Being a whiz at math is enough to compensate a woman for her lack of mechanical background, at least while she is in school. But as long as this is the only kind of woman who becomes an engineer, their number will remain small." (p. 181). 
Table 2: Reported out-of-school experiences for engineering students by gender. Percentages for experiences of all students by gender are included in parentheses for comparison.

\begin{tabular}{ccccc}
\hline $\begin{array}{c}\text { Out-of-school } \\
\text { Experience }\end{array}$ & $\begin{array}{c}\text { Percentage } \\
\text { Engineering Female } \\
\text { (All Females) }\end{array}$ & $\begin{array}{c}\text { Percentage } \\
\text { Engineering Male } \\
\text { (All Males) }\end{array}$ & Significance $^{\mathbf{a}}$ & $\mathbf{w}^{\mathbf{b}}$ \\
\hline tinkm & $38.6(23.2)$ & $65.5(47.7)$ & $* * *$ & 0.61 \\
tinke & $39.5(26.3)$ & $66.4(51.8)$ & $* * *$ & 0.61 \\
chem & $48.4(37.3)$ & $45.2(38.5)$ & $\mathrm{n} / \mathrm{s}$ & 0.07 \\
animal & $51.8(49.4)$ & $49.5(47.1)$ & $\mathrm{n} / \mathrm{s}$ & 0.05 \\
plant & $39.2(29.9)$ & $27.2(26.2)$ & $* * *$ & 0.30 \\
star & $31.6(23.6)$ & $30.5(27.9)$ & $\mathrm{n} / \mathrm{s}$ & 0.02 \\
group & $35.2(20.1)$ & $28.4(21.2)$ & $* *$ & 0.17 \\
comp & $33.6(16.9)$ & $29.5(21.3)$ & $\mathrm{n} / \mathrm{s}$ & 0.10 \\
nonfic & $48.4(48.5)$ & $52.5(45.8)$ & $\mathrm{n} / \mathrm{s}$ & 0.09 \\
scifi & $44.8(39.0)$ & $58.3(52.9)$ & $* * *$ & 0.23 \\
game & $43.5(34.6)$ & $75.0(69.6)$ & $* * *$ & 0.75 \\
prog & $24.0(17.5)$ & $32.9(30.0)$ & $* * *$ & 0.24 \\
talk & $59.9(40.4)$ & $59.5(46.7)$ & $\mathrm{n} / \mathrm{s}$ & 0.01 \\
\hline \hline
\end{tabular}

a. Significance calculated using chi-square test. The level of statistical significance is coded in the final column: $\mathrm{n} / \mathrm{s}$ represents a non-significant result, ** represents a statistical significance less than 0.01 but greater than or equal to 0.001 , and $* * *$ represents a statistical significance less than 0.001 .

b. Effect size calculated using Cohen's w. Effect sizes are indicated as small 0.10, medium 0.30, and large 0.50 .

A practical example of this can also be seen in traditionally taught thermodynamics classes in the discussion of an Otto cycle. This cycle is typically taught in most text books by describing a 4cycle engine ${ }^{38}$ often without detailed discussion about how an ignition piston system works. This example scaffolds tinkering experiences that vastly more male engineering students (65.5\%) have than female engineering students (38.6\%). Creating ways to incorporate all students' interests in the classroom may help make engineering more accessible and recruit and retain more women in engineering fields ${ }^{39}$. One way to scaffold thermodynamics concepts is to provide students with the opportunity to interact with a piston system within the classroom rather than assuming that students naturally have this prior knowledge because they are engineering students. This intervention could create the mental models needed to better understand classroom discussions and the PV diagrams taught in traditional thermodynamics courses. Differences in students' interest and involvement with these tinkering of out-of-school experience may explain some of the variability in numbers of women between engineering disciplines, especially their low numbers in mechanical, electrical, and computer engineering ${ }^{29}$. By understanding how these outcomes impact student choice, interest in these subjects may be fostered, especially by parents ${ }^{40-42}$, to encourage students to choose engineering in college.

Subsequent analysis were conducted to determine the impact of out-of-school experiences on how strongly students saw themselves as an engineer now (Table 3) and in the future (Table 4) for the entire sample of 15,847 students. A whole sample analysis was conducted to understand 
how specific STEM-related out-of-school experiences can encourage student identity development and engineering choice in college.

Table 3. Effect of out-of-school experiences on engineering possible self now.

\begin{tabular}{|c|c|c|c|c|c|c|}
\hline \multirow{2}{*}{$\begin{array}{l}\text { Out-of-school } \\
\text { Experience }\end{array}$} & \multicolumn{3}{|c|}{ Main Effects Model } & \multicolumn{3}{|c|}{ Interaction Model } \\
\hline & Estimate & Std. Error & Significance $^{c}$ & Estimate & Std. Error & Significance $^{\mathrm{c}}$ \\
\hline tinkm & 0.376 & 0.030 & $* * *$ & 0.538 & 0.042 & $* * *$ \\
\hline tinke & 0.326 & 0.029 & $* * *$ & 0.469 & 0.041 & $* * *$ \\
\hline animal & -0.111 & 0.029 & $* * *$ & -0.216 & 0.033 & $\mathrm{n} / \mathrm{s}$ \\
\hline plant & -0.130 & 0.025 & $* * *$ & -0.220 & 0.038 & $\mathrm{n} / \mathrm{s}$ \\
\hline group & 0.165 & 0.029 & $* * *$ & 0.174 & 0.033 & $* * *$ \\
\hline comp & 0.244 & 0.032 & $* * *$ & 0.244 & 0.033 & $* * *$ \\
\hline prog & 0.242 & 0.033 & $* * *$ & 0.327 & 0.043 & $* * *$ \\
\hline talk & 0.236 & 0.026 & $* * *$ & 0.327 & 0.035 & $* * *$ \\
\hline gender $(\mathrm{M}=0 ; \mathrm{F}=1)$ & -0.851 & 0.025 & $* * *$ & -0.620 & 0.042 & $* * *$ \\
\hline tinkm $x$ gender & & & & -0.342 & 0.060 & $* * *$ \\
\hline tinke $x$ gender & & & & -0.284 & 0.058 & $* * *$ \\
\hline animal x gender & & & & 0.158 & 0.051 & $* *$ \\
\hline plant $x$ gender & & & & 0.192 & 0.058 & $* * *$ \\
\hline prog x gender & & & & -0.188 & 0.060 & $* *$ \\
\hline talk $x$ gender & & & & -0.167 & 0.052 & $* *$ \\
\hline Adjusted R ${ }^{2}$ & & 0.189 & & & 0.198 & \\
\hline $\mathbf{N}$ & & 13,803 & & & 13,803 & \\
\hline
\end{tabular}

c. The level of statistical significance is coded in the final column: $\mathrm{n} / \mathrm{s}$ represents a non-significant result, ** represents a statistical significance less than 0.01 but greater than or equal to 0.001 , and ${ }^{* * *}$ represents a statistical significance less than 0.001 .

The regressions for feeling like an engineer now and in the future were built by including all of the possible out-of-school experiences plus gender as a block in a main effects model and then adding gender interactions to the model to create an interaction model. Tinkering with either mechanical or electrical devices was a positive predictor of feeling like an engineer now and in the future. Also, participating in competitions, writing computer programs, and talking with friends and family about science were significant predictors of feeling like an engineer both now and in the future. Participating in science groups/clubs/camps was the only predictor that was non-significant for feeling like an engineer in the future, but significant for feeling like an engineer now. The experiences of caring for an animal, engaging in nature, and playing computer/video games were non-significant for students seeing themselves as an engineer now, but were significant for feeling like an engineer in the future. Observing stars and reading/watching non-fiction science and science fiction were non-significant in the first addition of experiences in either of the engineering identity models. The main effect of gender in both models was negative. While not surprising based on knowledge of gendered perceptions of engineering and lack of women choosing engineering in college, this effect illustrates that there is a continued need for research in understanding underrepresentation in engineering. Being 
female not only was a negative predictor of an engineering identity for most students, but it was an even stronger negative predictor of feeling like an engineer in the future or seeing a possible self as an engineer.

Similar gender interactions were found across feeling like an engineer now and in the future analyses. Being female and indicating interest in tinkering with mechanical or electrical devices decreased the likelihood of reporting feeling like an engineer both now and in the future, and these estimates are larger than the direct predictors associated with predicting engineering possible selves. Talking about science with friends and family shows a negative interaction effect on feeling like an engineer now and in the future; however, the interaction model shows less of a negative effect than the main effects model for engineering identity now. These talks may have net positive effect for women in short-term identity development. Interest in programming and talking with friends and family about science along with being female decreased the likelihood of feeling like an engineer now. Participating in caring for an animal and interacting with the natural world and being male were positive predictors of feeling like an engineer both now and in the future.

Table 4. Effect of out-of-school experiences on engineering possible self in the future.

\begin{tabular}{|c|c|c|c|c|c|c|}
\hline \multirow{2}{*}{$\begin{array}{l}\text { Out-of-school } \\
\text { Experience }\end{array}$} & \multicolumn{3}{|c|}{ Main Effects Model } & \multicolumn{3}{|c|}{ Interaction Model } \\
\hline & Estimate & Std. Error & Significance $^{\mathrm{c}}$ & Estimate & Std. Error & Significance $^{c}$ \\
\hline tinkm & 0.382 & 0.034 & $* * *$ & 0.547 & 0.048 & $* * *$ \\
\hline tinke & 0.414 & 0.033 & $* * *$ & 0.602 & 0.047 & $* * *$ \\
\hline animal & -0.151 & 0.029 & $* * *$ & -0.253 & 0.038 & $* * *$ \\
\hline plant & -0.124 & 0.033 & $* * *$ & -0.279 & 0.043 & $* * *$ \\
\hline comp & 0.273 & 0.036 & $* * *$ & 0.277 & 0.036 & $* * *$ \\
\hline game & 0.081 & 0.031 & $* *$ & 0.093 & 0.031 & $* *$ \\
\hline prog & 0.264 & 0.035 & $* * *$ & 0.261 & 0.035 & $* * *$ \\
\hline talk & 0.313 & 0.030 & $* * *$ & 0.422 & 0.040 & $* * *$ \\
\hline gender $(\mathrm{M}=0 ; \mathrm{F}=1)$ & -1.080 & 0.030 & $* * *$ & -0.889 & 0.048 & $* * *$ \\
\hline tinkm $x$ gender & & & & -0.355 & 0.068 & $* * *$ \\
\hline tinke $x$ gender & & & & -0.368 & 0.066 & $* * *$ \\
\hline animal $x$ gender & & & & 0.163 & 0.058 & $* *$ \\
\hline plant $x$ gender & & & & 0.307 & 0.066 & $* * *$ \\
\hline talk $x$ gender & & & & -0.193 & 0.058 & $* * *$ \\
\hline Adjusted $\mathbf{R}^{2}$ & & 0.208 & & & 0.215 & \\
\hline $\mathbf{N}$ & & 13,875 & & & 13,875 & \\
\hline
\end{tabular}

c. The level of statistical significance is coded in the final column: $\mathrm{n} / \mathrm{s}$ represents a non-significant result, ** represents a statistical significance less than 0.01 but greater than or equal to 0.001 , and $* * *$ represents a statistical significance less than 0.001 .

These gender interactions highlight some possible reasons for why women choose engineering at lower rates than men. If they are having out-of-school experiences that are incompatible with seeing themselves as an engineer both now and in the future, then they may not choose a career incompatible with their identity. Women are usually credited with bringing many skills to engineering disciplines such as managing, planning, organizing, coordinating communications, 
and offering different perspectives, these features are often not recognized as fundamental engineering skills. The emphasis falls to technical and analytical skills ${ }^{43}$. Women must not only author their identity as engineers but must also contradict the traditional stereotypes surrounding engineering as a masculine field. The authoring of an engineering identity is not a one-time effort while pursuing a degree in engineering but is a continual process ${ }^{44}$. Traditionally, the engineering field holds a professional ideology that puts emphasis on mathematical ability and technical expertise. This environment along with the masculine stereotype of engineering contributes to creating a condition that is particularly unwelcoming to women ${ }^{45}$. This perceived incompatibility between women's gender and STEM identity is one reason researchers cite for the lack of representation of women in STEM fields ${ }^{46,47}$. These women experience heightened stress, tend to doubt their ability to perform, develop negative achievement expectations, and report lower performance, despite previous success in their area of study ${ }^{48,49}$. Developing an identity in STEM early has been shown to increase STEM enrollment in college and persistence $^{50}$. Understanding which STEM identities play into an engineering decision is a key part of understanding why women choose engineering in college and how to recruit and retain more from this underrepresented group.

Engineering choice is significantly impacted by students' engineering identities both now and in the future (Table 5). Feeling like an engineer now increased the likelihood of choosing an engineering career by approximately twenty percent. Interestingly, feeling like an engineer in the future increased the odds of choosing an engineering career in college by two and a half times or 250 percent. The stronger effect of holding an engineering possible self on choosing engineering has significant implications for how students select engineering in college and their motivation to remain in engineering over time. While subject-related identities in math and science have proven important for both men and women in their choice of engineering ${ }^{25}$, a future identity in engineering, or possible self may be a stronger link to engineering decisions.

Table 5. Effect of current engineering identity, engineering possible self, and gender on engineering choice in college.

\begin{tabular}{ccccc}
\hline Predictor & Estimate & Std. Error & Odds Ratio $^{\mathbf{d}}$ & Significance $^{\mathbf{c}}$ \\
\hline Engineer now & 0.187 & 0.031 & 1.20 & $* * *$ \\
Engineer in future & 0.917 & 0.033 & 2.50 & $* * *$ \\
Gender $(\mathrm{M}=0 ; \mathrm{F}=1)$ & -0.642 & 0.143 & 0.53 & $* * *$ \\
Gender*Engineer now & 0.163 & 0.048 & 1.18 & $* * *$ \\
\hline \hline
\end{tabular}

c. The level of statistical significance is coded in the final column: $\mathrm{n} / \mathrm{s}$ represents a nonsignificant result, ${ }^{* *}$ represents a statistical significance less than 0.01 but greater than or equal to 0.001 , and $* * *$ represents a statistical significance less than 0.001 .

d. The Odds ratio is the exponentiation of the Estimate.

Being female decreases the likelihood of choosing engineering in college by approximately one half times. From a young age, women face barriers to majoring in engineering in college. Primary school experiences lead young girls to view the physical sciences as masculine and the life sciences as feminine ${ }^{51}$. In middle school, it is common for girls to lose interest in both science and math classes ${ }^{52}$. In high school, girls take fewer Advanced Placement mathematics and science courses than boys, and a prevailing misconception is that boys significantly outperform girls in these areas ${ }^{53,54}$. Prior to college, young women receive minimal encouragement to major in engineering and lack role models in the field ${ }^{55}$. The consequence of 
these and other barriers is disproportionately low enrollment of women in engineering degree programs $^{29}$.

Despite these barriers, the interaction of being female and feeling like an engineer now may help buffer some of these experiences. This interaction increases the likelihood of choosing an engineering career by approximately twenty percent. If female students can develop feelings that they indeed are engineers and belong in engineering classes, the engineering community, and with their engineering peers early on, they may choose and stay in engineering at higher rates. Branding engineering in line with students' interests can help create more positive perceptions of a career in this field ${ }^{56}$. For women, these interests are more strongly related to natural sciences rather than tinkering or programming.

In their recent paper, authors Bieri Buschor, Berweger, Keck Frei and Kapper ${ }^{50}$ conducted a mixed method study of high school girls and their choices of a STEM career over two years. The results of this study show that occupational self-concept was negatively associated with choice of a STEM career. Most women saw their possible careers outside of STEM; however, early interest in science and strong math ability mitigated those effects. Additionally, women's perceived fit between their interest and study was positively associated with choosing a STEM career. In student narratives, the authors found that early interest in science was a trigger for choice of a STEM career later in life. These results shed some light onto the persistent issues of underrepresentation of women in engineering, but do not delve into how students' out-of-school experiences may play into these interest components and authoring of possible selves for motivation in engineering career choices. This paper focused on students' experiences during grades 9-12. From Bieri and collegues ${ }^{50}$, future work could include examining how students' experiences earlier on in P-8 grades affect students STEM-related interests and engineering identities now and the future.

The findings from this work begin to highlight how important out-of-school experiences can be for fostering student interest in engineering fields and their perceptions of their possible selves both now and in the future. These results have several implications for faculty in engineering courses, especially early on in students' post-secondary academic careers. First, when planning engineering curriculum, it is important to know that, on average, males and females may have been engaged in different out-of-school activities before coming to college. However, instructors should be careful not to approve of, or reinforce, stereotypical gender roles, which are likely to lie behind the results of this study as well. Assuming that a classroom of engineers has experiences in tinkering or using tools, in particular, may be a poor connection to students' prior knowledge, especially women's. When scaffolding students' prior knowledge and connecting engineering to real life in the classroom, referencing more male-associated out-of-school contexts may highlight the gender conflict many women experience in engineering. Second, to enhance students' motivation to remain in engineering it may be helpful to reference out-ofschool experiences that are positive predictors of possible selves for both men and women (e.g. participating in science/math competitions, or playing computer or video games).

A strength of the cross-sectional methodology used in this paper is the ability to draw conclusions from a national sample of college students. Also, we were able to test hypotheses related to factors and events that occurred naturally in students' experiences, rather than being 
restricted to student variables that could be manipulated in an intervention setting. A notable weakness of this methodology is that it can draw only correlational, not causal, conclusions. The correlational results reported here are strong, in many cases, but further work is necessary to investigate the causal relationships underlying the results reported here. Additionally, all of the regression estimates reported were standardized for comparison across predictors. While each out-of-school experience may have a small effect on engineering identities, the adjusted $\mathrm{R}^{2}$ values reported for each regression show that out-of-school experiences collectively account for approximately one-fifth of the variance in feeling like an engineer now and in the future.

\section{Conclusion}

The findings from this work have implications for pedagogy in introductory engineering courses. Understanding how informal learning experiences and interest in high school can affect possible selves may create opportunities to create more connections to students' prior knowledge, interests, and relatable every day experiences. This work also shows that engineering is not homogenous in the types of students and backgrounds that it attracts.

In the future, it would be useful to extend this work by differentiating between the subdisciplines of engineering. It would also be important to understand how out-of-school experiences, prior to college, impact the student attitudes reported here. This future work would give a clearer explanation for how students get directed towards engineering, a critical piece of information in the improvement of the recruitment and retention of the next generation of engineers. Another future application of this work is to incorporate some of these findings into the curricula of engineering programs and make these findings practical for engineering educators.

\section{References}

1. President's Council of Advisors on Science and Technology. Engage to Excel: Producing One Million Additional College Graduates with Degrees in Science, Technology, Engineering, and Mathematics; 2012; p. 130.

2. Teitelbaum, M. S. The Atlantic. March 2014, p. 2.

3. The U.S. Scientific and Technical Workforce: Improving Data for Decision Making; Kelly, T. K.; Butz, W.; Carroll, S. J.; Adamson, D. M.; Bloom, G., Eds.; RAND Corporation, 2004; p. 134.

4. Miller, J. A. The Science and Engineering Workforce: Realizing America’s Potential.; 2003.

5. Godwin, A. Understanding Female Engineering Enrollment: Explaining Choice with Critical Engineering Agency (Doctoral Dissertation), Clemson University, 2014, p. 248.

6. $\quad$ Markus, H.; Nurius, P. Am. Psychol. 1986, 41, 954.

7. $\quad$ Burke, P. J.; Stets, J. E. Identity theory; Oxford University Press, 2009.

8. Oyserman, D.; Brickman, D.; Rhodes, M. Fam. Relat. 2007, 56, 479-489.

9. Oyserman, D.; Bybee, D.; Terry, K.; Hart-Johnson, T. J. Res. Pers. 2004, 38, 130-149.

10. Oyserman, D.; Destin, M.; Novin, S. Self Identity 2014, 1-16.

11. Fugate, M.; Kinicki, A. J.; Ashforth, B. E. J. Vocat. Behav. 2004, 65, 14-38.

12. Ibarra, H. Adm. Sci. Q. 1999, 44, 764-791. 
13. Ibarra, H. Identity transitions: possible selves, liminality and the dynamics of career change; 2005.

14. Kerpelman, J. L.; Pittman, J. F. J. Adolesc. 2001, 24, 491-512.

15. Godwin, A.; Potvin, G. Int. J. Eng. Educ. (In Press. 2015.

16. Pizzolato, J. E. Cultur. Divers. Ethnic Minor. Psychol. 2006, 12, 57-69.

17. Committee on K-12 Engineering Education. Engineering in K-12 education: Understanding the Status and Improving the Prospects; Katehi, L.; Pearson, G.; Feder, M. A., Eds.; The National Academies Press: Washington, D.C., 2009; p. 234.

18. Aloise-Young, P. A.; Hennigan, K. M.; Leong, C. W. J. Early Adolesc. 2001, 21, 158-181.

19. Oyserman, D.; Markus, H. J. Soc. Issues 1990, 46, 141-157.

20. Rennie, L. J.; Fehrer, E.; Dierking, L. D.; Falk, J. H. J. Sci. Teacher Educ. 2002, 40, 112-120.

21. Hazari, Z.; Sonnert, G.; Sadler, P. M.; Shanahan, M.-C. C. J. Res. Sci. Teaching. 2010, 47, 978-1003.

22. Bell, P.; Lewenstein, B.; Shouse, A. W.; Feder, M. A. Learning Science in Informal Environments: People, Places, and Pursuits; Washington, D.C., 2009.

23. Renninger, A.; Hidi, S.; Krapp, A. The role of interest in learning and development; Psychology Press, 2014.

24. Lent, R. W. W.; Brown, S. D. D.; Hackett, G. J. Vocat. Behav. 1994, 45, 79-122.

25. Godwin, A.; Potvin, G.; Hazari, Z.; Lock, R. J. Eng. Educ. 2015.

26. Maltese, A. V.; Tai, R. H. Int. J. Sci. Educ. 2010, 32, 669-685.

27. Nazier, G. L. Sch. Sci. Math. 2010, 93, 321-327.

28. Jones, G.; Howe, A.; Rua, M. Sci. Educ. 2000, 84, 180-192.

29. Yoder, B. L. Engineering by the Numbers; 2013; p. 37.

30. R Core Team. R: A language and environment for statistical computing, 2013.

31. Engineering - Curriculum www.pltw.org/our-programs/engineering/engineering-curriculum.

32. Coyle, E. J.; Jamieson, L. H.; Oakes, W. C. Int. J. Eng. Educ. 2005, 21, 139-150.

33. Aschbacher, P. R.; Li, E.; Roth, E. J. J. Res. Sci. Teach. 2010, 47, 564-582.

34. Godwin, A.; Potvin, G. In American Educational Research Association Annual Meeting; Philadelphia, PA, 2014.

35. Jones, M. G.; Howe, A.; Rua, M. J. Sci. Educ. 2000, 84, 180-192.

36. Wang, J.; Werner-Avidon, M.; Newton, L.; Randol, S.; Smith, B.; Walker, G. J. Pre-College Eng. Educ. Res. 2013, 3, 2.

37. McIlwee, J. S.; Robinson, J. G. Women in engineering: Gender, power, and workplace culture; SUNY Press, 1992.

38. Modell, M.; Reid, R. C. Thermodynamics and its Applications; Prentice-Hall Englewood Cliffs, NJ, 1974.

39. Richardson, A. L. Tinkering self-efficacy and team interaction on freshman engineering design teams; ProQuest, 2008.

40. $\quad$ Eccles, J.; Harold, R. Teach. Coll. Rec. 1993, 94, 568-587.

41. Eshach, H. J. Sci. Educ. Technol. 2007, 16, 171-190.

42. Mau, W.-C. Career Dev. Q. 2003, 51, 234-243.

43. Cech, E.; Rubineau, B.; Silbey, S.; Seron, C. Am. Sociol. Rev. 2011, 76, 641-666.

44. Johnson, A.; Brown, J.; Carlone, H.; Cuevas, A. J. Res. Sci. Teaching. 2011, 48, 339-366.

45. Jorgenson, J. Manag. Commun. Q. 2002, 15, 350-380.

46. Hill, C.; Corbett, C.; St Rose, A. Why so few? Women in science, technology, engineering, and mathematics; Washington, D.C., 2010.

47. $\quad$ Rosenthal, L.; London, B.; Levy, S. R.; Lobel, M. Sex Roles 2011, 65, 725-736.

48. Ancis, J. R.; Phillips, S. D. J. Couseling Dev. 1996, 75, 131-137.

49. London, B.; Rosenthal, L.; Levy, S. R.; Lobel, M. Basic Appl. Psychol. 2011, 33, 304-321. 
50. $\quad$ Bieri Buschor, C.; Berweger, S.; Keck Frei, A.; Kapper, C. J. Educ. Res. 2014, 107, 167-176.

51. Clewell, B. C.; Campbell, P. B. J. Women Minor. Sci. Eng. 2002, 8, 255-284.

52. Miller Jr., J. A. The Science and Engineering Workforce: Realizing America's Potential. Rep. No. NSB 0379; 2003.

53. Freeman, C. E. Trends in Educational Equity of Girls \& Women. Washington, DC: US Government Printing Office: US Department of Education; Washington, D.C., 2004.

54. Hyde, J. S.; Lindberg, S. M.; Linn, M. C.; Ellis, A. B.; Williams, C. C. Science. 2008, 321, 494-496.

55. Seymour, E. Ann. N. Y. Acad. Sci. 1999, 869, 118-126.

56. Committee on Public Understanding of Engineering Messages. Changing the conversation: messages for improving public understanding of engineering; 2008. 